\title{
Sex-based differences in factors associated with bronchial hyperresponsiveness in adolescents with childhood asthma
}

\author{
Young Hwan Kim, MD, Yoon Young Jang, MD, Jieun Jeong, MD, Hai Lee Chung, MD \\ Department of Pediatrics, School of Medicine, Daegu Catholic University, Daegu, Korea
}

Background: Bronchial hyperresponsiveness (BHR), an important physiological feature of asthma, is a prognostic marker of childhood asthma.

Purpose: We aimed to investigate the factors associated with BHR in adolescents with childhood asthma.

Methods: Two hundred and fifteen adolescents ( $\geq 13$ years of age; 149 males, 66 females) who were diagnosed with asthma during childhood were enrolled, underwent methacholine challenge tests, and were divided into the BHR group $(<25$ $\mathrm{mg} / \mathrm{mL}$ of provocation concentration causing a $20 \%$ fall in forced expiratory volume in 1 second $\left[\mathrm{FEV}_{1}\right]\left[\mathrm{PC}_{20}\right], \mathrm{n}=113$ ) or non-BHR group ( $\geq 25 \mathrm{mg} / \mathrm{mL}$ of $\mathrm{PC}_{20}, \mathrm{n}=102$ ). We examined longitudinal changes in $\mathrm{BHR}$ and the risk factors for its persistence in the 108 adolescents for whom baseline data, including methacholine $\mathrm{PC}_{20}$ at age 6 years, were available. Multivariate logistic regression analyses were performed to assess the factors associated with BHR in adolescents.

Results: Mold sensitization (adjusted odds ratio [aOR], 5.569; $P=0.005)$ and increased blood eosinophil count $(\mathrm{aOR}$, 1.002; $P=0.026$ ) were independently associated with BHR in boys but not girls. The odds of BHR decreased by $32 \%$ with each 1 -year increase in age in boys $(\mathrm{aOR}, 0.683 ; P=0.010)$ but not girls. A reduced $\mathrm{FEV}_{1} /$ forced vital capacity ratio $(<90 \%)$ was independently related with BHR in female patients only (aOR, 7.500; $P=0.007)$. BHR decreased with age throughout childhood. A low methacholine $\mathrm{PC}_{20}$ at age 6 years was independently associated with persistent BHR throughout childhood in male and female patients, whereas early mold sensitization was a risk factor for persistent BHR in male patients only (aOR, $7.718 ; P=0.028)$.

Conclusion: Our study revealed sex-specific differences in the factors associated with BHR in adolescents with childhood asthma. Our findings suggest the risk factors that might affect asthma transition from childhood to adolescence and adulthood.

Key words: Adolescence, Asthma, Bronchial hyperresponsiveness, Mold, Sex

\section{Key message}

Question: What factors are associated with bronchial hyperresponsiveness (BHR) in adolescents with childhood asthma?

Finding: Age, mold sensitization, and increased eosinophil count were associated with BHR in boys versus a reduced forced expiratory volume in 1 second/forced vital capacity ratio in girls. Early mold sensitization was a risk factor for persistent BHR in boys only.

Meaning: Sex-specific differences were observed in the factors associated with BHR in adolescents.

\section{Introduction}

Bronchial hyperresponsiveness (BHR) is characterized by excessive airway narrowing in response to provoking stimuli, which is the most important pathophysiologic feature of asthma. ${ }^{1)}$ Assessment of BHR is a main diagnostic criterion of asthma, and it can be an indicator related to the severity and prognosis of asthma.,3)

Adolescence is a time of remission in many children with asthma. However, previous longitudinal studies have reported that symptom remission does not reflect remission of underlying airway pathology and asymptomatic patients still have abnormal lung function and/or persisting BHR. ${ }^{4-6)}$ Asthma cohort studies reported that BHR that was already present in preschool age was a predictor of newly diagnosed asthma in early adulthood, ${ }^{7}$ and that asthma relapse in adulthood was associated with asymptomatic BHR in adolescence. ${ }^{8)}$ Adolescence is a critical link between childhood and adulthood when childhood asthma may change significantly, but published literature examining the transition process in the adolescents with childhood asthma is not much yet. ${ }^{9,10)}$

Methacholine challenge test (MCT) is the most frequently used method to asses BHR. According to American Thoracic Society (ATS) guideline, BHR to diagnose pediatric asthma is considered as the level of methacholine for the forced expiratory volume in 1 second $\left(\mathrm{FEV}_{1}\right)$ to drop $20 \%$ from baseline (provocative concentration of methacholine causing a $20 \%$ fall

Corresponding author: Hai Lee Chung, MD. Department of Pediatrics, School of Medicine, Daegu Catholic University, 33 Duryugongwon-ro $17-g i l$, Nam-gu, Daegu 42472, Korea 
in $\mathrm{FEV}_{1}, \mathrm{PC}_{20}$ ) to be less than or equal to $16 \mathrm{mg} / \mathrm{mL}^{.11)} \mathrm{BHR}$ is known to decrease with age through childhood, ${ }^{12,13)}$ and a previous Korean study has suggested that the application of different cutoff values of methacholine $\mathrm{PC}_{20}$ depending on age might be practical for the diagnosis of asthma in adolescence. ${ }^{14)}$ In a recent report from the Childhood Asthma Management Program (CAMP), absence of BHR in adolescence was defined at a methacholine $\mathrm{PC}_{20}$ of $25 \mathrm{mg} / \mathrm{mL}$ or greater. ${ }^{15)}$

In the present study, we performed MCTs in the adolescents who had childhood asthma and examined the factors associated with BHR and investigated if there were sex-specific differences. In the subjects whose baseline data at age 6 including the results of the initial MCTs were available, we examined longitudinal change of BHR through childhood and also analyzed sexspecific differences in the factors associated with the persistent BHR into adolescence. Our study aimed to investigate the factors that might be involved in asthma transition from childhood into adolescence and adulthood.

\section{Methods}

\section{Subjects}

In the present study, 215 adolescents (age of 13 years or more) who were previously diagnosed and treated with asthma during childhood were enrolled. They performed MCTs during the period between January 2017 and December 2019 at Daegu Catholic University Hospital. They had been diagnosed as having childhood asthma by their physicians; they had recurrent wheezing which persisted after 3 years of age and showed BHR upon direct or indirect bronchial challenge tests carried out during childhood. Asthma severity of the patients was assessed according to Global Initiative for Asthma criteria as suggested in a recent study ${ }^{16)}$ and graded from 1 to 4 in this study; 1; mild- intermittent, 2; mild-persistent, 3; moderate-persistent, 4; severe-persistent.

The subjects were divided into 2 groups based on the presence of BHR defined according to CAMP criteria ${ }^{15)}$ : BHR group $\left(<25 \mathrm{mg} / \mathrm{mL}\right.$ of methacholine $\left.\mathrm{PC}_{20}, \mathrm{n}=113\right)$ and non-BHR group ( $\geq 25 \mathrm{mg} / \mathrm{mL}$ of methacholine $\mathrm{PC}_{20}, \mathrm{n}=102$ ). We also divided each sex group, 149 males and 66 females, by the presence of BHR. Patients with congenital heart disease, chronic respiratory disease other than asthma, or any underlying disease were excluded.

In the present study, 108 subjects performed the first bronchial challenge tests at age 6 with methacholine and were diagnosed as having $\mathrm{BHR}$ (defined as $\mathrm{PC}_{20} \leq 16 \mathrm{mg} / \mathrm{mL}$ ). Among those subjects, 40 showed persistent BHR into adolescence and 68 showed no more BHR. We divided the subjects by the persistence of BHR within each sex group, 71 males and 37 females, and analyzed the relationship between the baseline data at age 6 and persistent BHR through childhood.

Flow chart of the study is presented in Fig. 1. Informed consents were obtained from all patients and their parents, and this study was approved by the Daegu Catholic University Medical Center Institutional Review Board (CR-20-078).

\section{Clinical characteristics of the subjects}

Medical records of the subjects were reviewed retrospectively. Clinical characteristics such as age at the 1st wheeze started, hospitalization related to lower respiratory tract infection before age 3, combined other allergic diseases, family history of allergy, atopic sensitization, sensitized allergens, and body mass index were examined.

Current asthma was defined as having episodes of wheeze verified by pediatric specialists or asthma exacerbation in the previous year at the time of MCT.

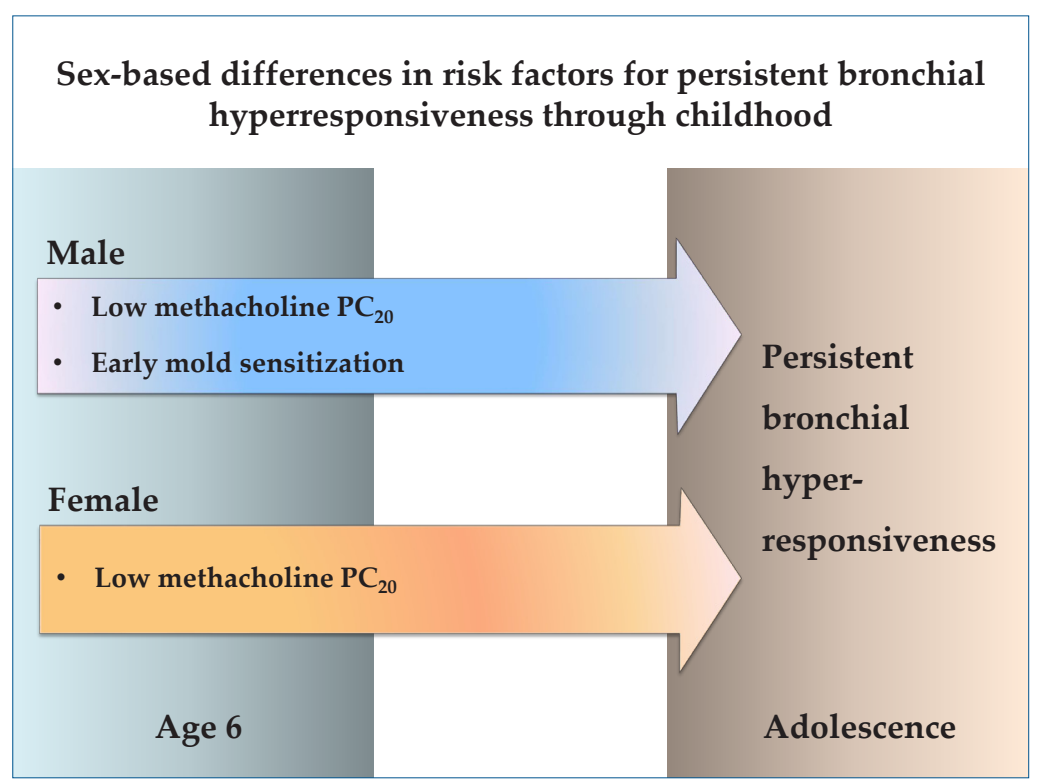

Graphical abstract. $P_{20}$, provocative concentration of methacholine causing a $20 \%$ fall in forced expiratory volume in 1 second. 


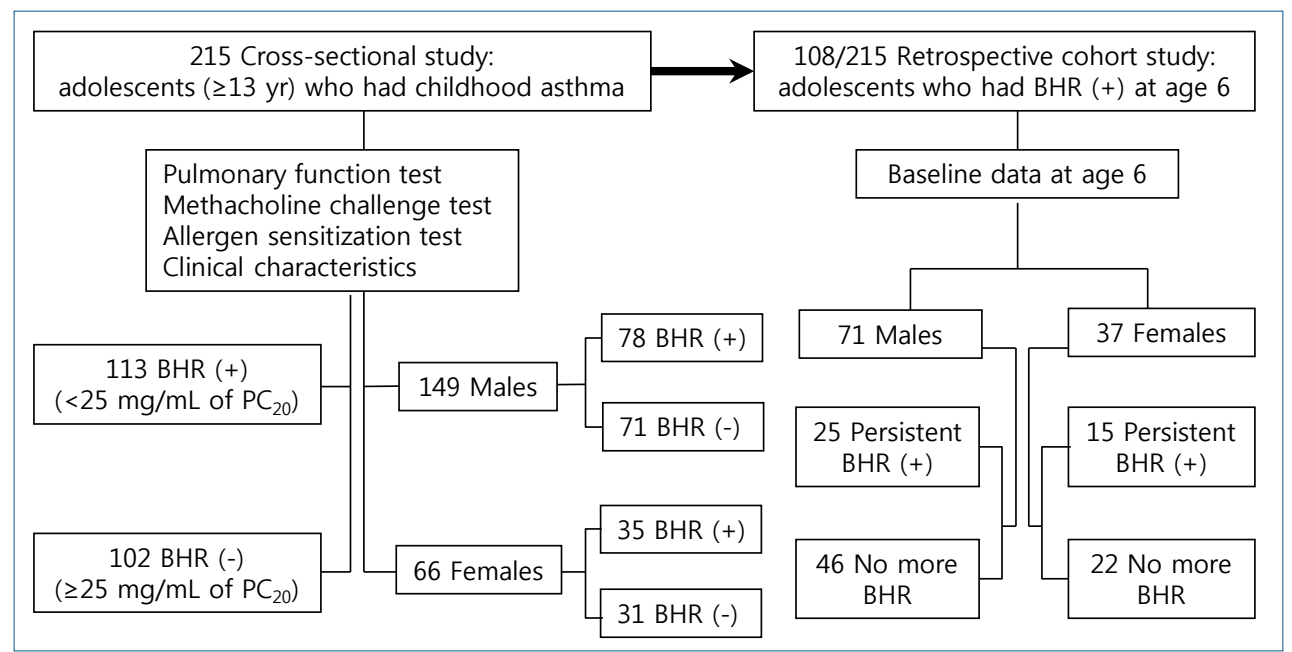

Fig. 1. Flow chart of adolescents with childhood asthma included in this study. BHR, bronchial hyperresponsiveness; $\mathrm{PC}_{20}$, provocation concentration causing a $20 \%$ fall in forced expiratory volume in 1 second.

\section{Pulmonary function test and MCT}

Pulmonary function tests were performed using SU 6000 SuperSpiro Spirometer (Micro Medical Ltd., Chatham, UK). $\mathrm{FEV}_{1}$, forced vital capacity (FVC), and $\mathrm{FEV}_{1} / \mathrm{FVC}$ ratio were measured. In this study, reduced $\mathrm{FEV}_{1} / \mathrm{FVC}$ was defined at a ratio of $<90 \%$, and well-preserved $\mathrm{FEV}_{1} / \mathrm{FVC}$ was defined at $\geq 90 \%$ as suggested in the previous study from CAMP cohort. ${ }^{15)}$

MCTs were conducted according to ATS guidelines using KoKo-MSM dosimeter (nSpire Health Inc., Louisville, CO, USA). Provocholine (Methacholine chloride USP, Methapharm Inc., Brantford, ON, Canada) solutions were prepared in buffered normal saline at concentrations of $0.0625,0.25,1,4,16$, $25 \mathrm{mg} / \mathrm{mL}$, and the subjects inhaled the methacholine solution with stepwise increasing concentration at 5-minute interval. The degree of BHR was categorized into 3 levels based on ATS criteria (moderate-to-severe $<1 \mathrm{mg} / \mathrm{mL}$, mild $1-4 \mathrm{mg} / \mathrm{mL}$, borderline $>4 \mathrm{mg} / \mathrm{mL}$ ). ${ }^{11)}$ MCTs were performed when the subjects were free from acute respiratory infection and had no asthma symptoms within the previous 4 weeks. The patients were instructed to withhold asthma medications, long-acting $\beta_{2}$ agonists, inhaled corticosteroids, and leukotriene antagonists for at least 72 hours prior to testing.

\section{Investigation of atopic sensitization}

Atopic sensitization was assessed by skin prick test or serum allergen-specific IgE test. The skin prick test was performed on 53 common allergens using commercially available reagents (Lofarma SpA, Milan, Italy), and allergen-specific IgE was meaured for house dust mite (HDM) (Dermatophagoides farinae, Dermatophagoides pteronyssinus), tree pollen mixture, grass pollen mixture, weed pollen mixture, mold mixture, cat, dog, and food allergens (egg, milk, soybean, peanut) using ImmunoCAP (Pharmacia Diagnostics, Uppsala, Sweden). Atopic sensitization was defined when the patients had at least one positive reaction to skin prick test or an allergen-specific $\operatorname{IgE}>0.35$ $\mathrm{kU} / \mathrm{L}$.

\section{Statistical analysis}

For statistical analysis, IBM SPSS Statistics ver. 25.0 (IBM Co., Armonk, NY, USA) was used. The chi-square test or Fisher exact test was used to compare categorical variables between the 2 groups. When comparing continuous variables with normal distribution between the 2 groups, Student $t$ test was used and the data were expressed as mean and standard deviation. MannWhitney $U$ test was used for nonnormally distributed data, which were expressed as median and interquartile range. Multivariate logistic regression analysis was performed to obtain the adjusted odds ratio (aOR) for factors associated with presence or persistence of BHR. The confidence interval (CI) was set to $95 \%$ and $P$ value less than 0.05 was considered statistically significant.

\section{Results}

\section{The factors associated with BHR in the adolescents who had childhood asthma}

Table 1 presents the clinical characteristics of 2 adolescent groups defined by the presence of BHR on univariate analyses. There were no differences between the 2 groups in mean age, sex distribution, age at the 1st wheeze started, and hospitalization for lower respiratory tract infection before age 3 .

The prevalence of combined allergic rhinitis was high in both groups. The prevalence of atopic dermatitis was higher in BHR group, which did not reach statistical significance $(P=0.092)$. Although the rate of atopic sensitization was high in both patient groups, pet sensitization rate was significantly higher $(P=0.009)$, and HDM and mold sensitization rate tended to be higher ( $P=0.054, P=0.050$, respectively) in BHR group compared with non-BHR group. Total serum IgE level was not different between the 2 groups, but peripheral blood eosinophil count was significantly higher in BHR group $(P=0.007)$. Asthma severity was significantly higher in BHR group than in non-BHR group $(P=0.001)$.

Current asthma was more common in BHR group $(P=0.000)$, 
Table 1. Clinical characteristics of asthmatic adolescents with or without bronchial hyperresponsiveness

\begin{tabular}{|c|c|c|c|}
\hline Characteristic & $\operatorname{BHR}(+)(n=113)$ & $\operatorname{BHR}(-)(n=102)$ & $P$ value \\
\hline Age (yr) & $14 \pm 2.4$ & $14 \pm 2.0$ & 1.000 \\
\hline Male sex & $78(69)$ & $71(70)$ & 0.956 \\
\hline \multicolumn{4}{|l|}{ Age at the 1st wheeze started (yr) } \\
\hline$<3$ & $42(37)$ & $43(42)$ & 0.465 \\
\hline$\geq 3,<6$ & $14(12)$ & $17(17)$ & 0.398 \\
\hline$\geq 6$ & $57(51)$ & $42(41)$ & 0.248 \\
\hline Admission with LRI during 1 st 3 years of life & $37(33)$ & $38(37)$ & 0.567 \\
\hline \multicolumn{4}{|l|}{ Combined allergic disease } \\
\hline Allergic rhinitis & $81(72)$ & $75(74)$ & 0.762 \\
\hline Atopic dermatitis & $55(49)$ & $38(37)$ & 0.092 \\
\hline Parental allergic disease & $45(40)$ & $36(35)$ & 0.494 \\
\hline Atopic sensitization & $106(94)$ & $90(88)$ & 0.228 \\
\hline House dust mite & $97(92)$ & $77(86)$ & 0.054 \\
\hline Tree pollen & $47(44)$ & $51(57)$ & 0.221 \\
\hline Grass pollen & $25(24)$ & $26(29)$ & 0.347 \\
\hline Weed pollen & $37(35)$ & $38(42)$ & 0.567 \\
\hline Mold & $34(32)$ & $19(21)$ & 0.050 \\
\hline Pet & $39(37)$ & $19(21)$ & 0.009 \\
\hline Food & $14(13)$ & $17(19)$ & 0.448 \\
\hline Polysensitization & $68(64)$ & $66(73)$ & 0.526 \\
\hline Total serum IgE (IU/mL), median (IQR) & $462(208.9-1,044)$ & $329(138.3-664.5)$ & 0.102 \\
\hline Eosinophil (count/mm³), median (IQR) & $561(279-778)$ & $400(208-602)$ & 0.007 \\
\hline Body mass index $\left(\mathrm{kg} / \mathrm{m}^{2}\right)$ & $21.7 \pm 4.1$ & $21.9 \pm 6.7$ & 1.002 \\
\hline Asthma severity, median (range) & $2(1-4)$ & $1(1-4)$ & 0.001 \\
\hline Pulmonary function test & - & $96 \pm 13.7$ & \\
\hline FEV 1 (\%predicted) & $91 \pm 14.4$ & $94 \pm 15.9$ & 0.013 \\
\hline FVC (\%predicted) & $94 \pm 13.7$ & $86 \pm 8.0$ & 1.000 \\
\hline $\mathrm{FEV}_{1} / \mathrm{FVC}(\%)$ & $84 \pm 10.5$ & $58(57)$ & 0.042 \\
\hline$<90$ & $87(77)$ & $44(43)$ & 0.002 \\
\hline$\geq 90$ & $26(23)$ & NA & - \\
\hline Methacholine $\mathrm{PC}_{20}(\mathrm{mg} / \mathrm{mL})$, median (IQR) & $5(1.4-16)$ & - & - \\
\hline$<1$ & $25(22)$ & - & - \\
\hline $1-4$ & $24(21)$ & - & - \\
\hline$>4$ & $64(57)$ & - & - \\
\hline Current asthma & $75(66)$ & $32(31)$ & 0.000 \\
\hline $\mathrm{PC}_{20},<1$ & $19 / 25(76)$ & - & $0.001^{a)}$ \\
\hline$P C_{20}, 1-4$ & 19/24 (79) & - & - \\
\hline $\mathrm{PC}_{20},>4$ & $37 / 64(58)$ & - & - \\
\hline
\end{tabular}

Values are presented as mean \pm standard deviation or number (\%) unless otherwise indicated.

$\mathrm{BHR}$, bronchial hyperresponsiveness; LRI, lower respiratory infection; IQR, interquartile range; FEV 1 , forced expiratory volume in 1 second; FVC, forced vital capacity; PC20, provocative concentration of methacholine causing a 20\% fall in forced expiratory volume in 1 second; NA, not available.

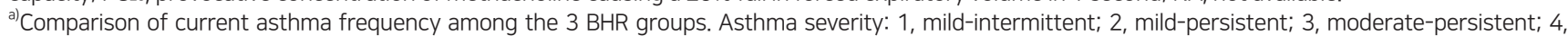
severe-persistent. Current asthma: episodes of wheeze verified by physicians or asthma exacerbation in the previous year.

Boldface indicates a statistically significant difference with $P<0.05$.

but 38 subjects (34\%) in BHR group had no current asthma. Current asthma in BHR group was significantly related with the severity of BHR. The subjects with $\mathrm{PC}_{20}$ less than 1 or $1-4 \mathrm{mg} /$ $\mathrm{mL}$ (moderate-to-severe or mild BHR) presented current asthma more commonly compared to those with $\mathrm{PC}_{20}$ greater than 4 $\mathrm{mg} / \mathrm{mL}$ (borderline BHR) $(P=0.001)$.

Pulmonary function test results showed significantly lower $\mathrm{FEV}_{1}$ \%predicted and $\mathrm{FEV}_{1} / \mathrm{FVC}$ ratio in BHR group than in non-BHRgroup $(P=0.013, P=0.042$, respectively). The subjects with reduced $\mathrm{FEV}_{1} / \mathrm{FVC}$ ratio $(<90 \%)$ were more frequently observed in BHR group, and those with well-preserved $\mathrm{FEV}_{1} /$ FVC ratio (defined as $\geq 90 \%$ in the previous study from CAMP cohort $\left.^{15)}\right)$ were more common in non-BHR group $(P=0.002)$.

In the multivariate analyses, sensitization to mold allergens remained to be independently associated with the presence of BHR (aOR, 4.038; 95\% CI, 1.572-10.373; $P=0.004$ ). The risk of BHR increased by 1.001 times with each 1 increase of peripheral blood eosinophil count (95\% CI, 1.000-1.001; $P=$ 
0.018). Reduced $\mathrm{FEV}_{1} / \mathrm{FVC}$ ratio (<90\%) (aOR, 3.106; 95\% CI, 1.000-1.174-8.219; $P=0.022)$ and current asthma (aOR, 2.496; 95\% CI, 1.118-5.568; $P=0.026$ ) were independently associated with BHR (Table 2).

\section{Sex-specific differences in the factors associated with BHR}

Univariate analyses of the factors associated with BHR in each sex group are presented in Table 3.

Atopic dermatitis showed a tendency to be related with the presence of BHR in the male subjects $(P=0.082)$, but not in female subjects. In the male subjects, atopic sensitization rate showed a tendency to be higher $(P=0.091)$, and sensitizations to mold and pet allergens were significantly higher in BHR group than in non-BHR group ( $P=0.047, P=0.041$, respectively). However, in the female subjects, no relationship was observed between those atopic factors and the presence of BHR.

The median values of methacholine $\mathrm{PC}_{20}$ in $\mathrm{BHR}$ groups showed no difference between the male and female subjects (male: 5.6 ; interquartile range [IQR], $1.3-16 \mathrm{mg} / \mathrm{mL}$ vs. female: $5.0 ; \mathrm{IQR}, 2.3-16 \mathrm{mg} / \mathrm{mL} ; P=0.72)$. In the male subjects, values of $\mathrm{FEV}_{1} \%$ predicted and $\mathrm{FEV}_{1} / \mathrm{FVC}$ ratio were not related with the presence of BHR. However, in the female subjects, $\mathrm{FEV}_{1} \%$ predicted and $\mathrm{FEV}_{1} / \mathrm{FVC}$ ratio were significantly lower in $\mathrm{BHR}$ group than in non-BHR group. ( $P=0.024, P=0.041$, respectively). The subjects with reduced $\mathrm{FEV}_{1} / \mathrm{FVC}$ ratio $(<90 \%)$ were also more frequently observed in the female subjects with BHR than in those without $(P=0.005)$.

In multivariate analyses, in the male subjects, the odds of BHR decreased by $32 \%$ with each 1-year increase in age $(\mathrm{aOR}$, 0.683; 95\% CI, 0.510-0.914; $P=0.010$ ), mold sensitization was independently associated with the presence of BHR (aOR, 5.569; 95\% CI, 1.702-18.221; $P=0.005)$, and the odds of BHR increased by 1.002 times with each 1 increase of peripheral blood eosinophil count (95\% CI, 1.000-1.003; $P=0.026$ ). In the female subjects, only reduced $\mathrm{FEV}_{1} / \mathrm{FVC}$ ratio $(<90 \%)$ was independently associated with the presence of BHR (aOR, 7.5; 95\% CI, 1.715-32.796; $P=0.007$ ) (Table 4).

Table 2. Multivariate logistic regression analyses of the factors associated with bronchial hyperresponsiveness in adolescents

\begin{tabular}{lccc}
\hline Variable & aOR & $95 \% \mathrm{Cl}$ & $P$ value \\
\hline Mold sensitization & 4.038 & $1.572-10.373$ & $\mathbf{0 . 0 0 4}$ \\
\hline Total serum $\mathrm{IgE}(\mathrm{IU} / \mathrm{mL})^{\mathrm{a})}$ & 1.001 & $1,000-1.001$ & 0.055 \\
${\text { Eosinophil }\left(\mathrm{count} / \mathrm{mm}^{3}\right)^{\mathrm{a})}}$ & 1.001 & $1,000-1.002$ & $\mathbf{0 . 0 1 8}$ \\
$\mathrm{FEV}_{1} \%^{\mathrm{a})}$ & 0.965 & $0.928-1.003$ & 0.073 \\
$\mathrm{FEV}_{1} / \mathrm{FVC}<90 \%{ }^{\mathrm{b})}$ & 3.106 & $1.174-8.219$ & $\mathbf{0 . 0 2 2}$ \\
\hline Current asthma & 2.496 & $1.118-5.568$ & $\mathbf{0 . 0 2 6}$ \\
\hline
\end{tabular}

$\mathrm{aOR}$, adjusted odds ratio; $\mathrm{Cl}$, confidence interval; $\mathrm{FEV}_{1}$, forced expiratory volume in 1 second; FVC, forced vital capacity.

Covariates included age, sex, atopic dermatitis, house dust mite/mold/pet sensitization, total serum immunoglobulin $\mathrm{E}$, eosinophil count, $\mathrm{FEV}_{1} \%$, $\mathrm{FEV}_{1} /$ FVC, and current asthma.

${ }^{\text {a) }}$ Quantitative variables were modeled continuously. ${ }^{\text {b) }}$ Quantitative variables were modeled categorically. Reference group was $F E V_{1} / F V C \geq 90 \%$.

Boldface indicates a statistically significant difference with $P<0.05$.

\section{Longitudinal change of BHR and sex-specific differences in the risk factors for persistent BHR through childhood into adolescence}

Among 108 subjects whose baseline data at age 6 including the results of the initial MCTs were available, 40 (37\%, 25 males and 15 females) showed persistent BHR in adolescence. Table 5 shows the baseline data at age 6 in 2 sex groups classified by the persistence of BHR into adolescence.

BHR decreased through childhood in both male and female adolescents. In male group, median value of methacholine $\mathrm{PC}_{20}$ increased from $2.3 \mathrm{mg} / \mathrm{mL}$ at age 6 to $15.2 \mathrm{mg} / \mathrm{mL}$ in adolescence, and in female group, from $2.6 \mathrm{mg} / \mathrm{mL}$ to $14.7 \mathrm{mg} / \mathrm{mL}$. Follow-up level of methacholine $\mathrm{PC}_{20}$ in the adolescents with persistent BHR showed no difference between the 2 sex groups (male: 15.2; IQR, 3.7-19.2 mg/mL vs. female: 14.7; IQR, 4.1$20.3 \mathrm{mg} / \mathrm{mL} ; P=0.826$ ).

In both sex groups, baseline methacholine $\mathrm{PC}_{20}$ values at age 6 were significantly lower in the subjects with persistent BHR compared with those with no more BHR: (persistent BHR: 2.3; IQR, 1.2-6.5 mg/mL vs. no more BHR: 10.5 ; IQR, 6.3-13.8 $\mathrm{mg} / \mathrm{mL} ; P=0.000$ ) in males and (persistent BHR: 2.6; IQR, $1.8-5.8 \mathrm{mg} / \mathrm{mL}$ vs. no more BHR: 9.8; IQR, $6.4-14.3 \mathrm{mg} / \mathrm{mL}$; $P=0.007$ ) in females. In both sex groups, the subjects with low baseline methacholine $\mathrm{PC}_{20}(\leq 4 \mathrm{mg} / \mathrm{mL})$ were more frequently observed in the adolescents with persistent BHR.

In both sex groups, the baseline factors at age 6 , such as, atopic sensitization, combined allergic diseases, total serum $\operatorname{IgE}$ levels, and blood eosinophil count were not associated with the persistent BHR in adolescence. However, in males, early sensitization to mold allergens at age 6 was significantly higher in the subjects with persistent BHR than in those with no more BHR $(P=0.013)$. In females, mean value of $\mathrm{FEV}_{1} \%$ predected was significantly lower in the subjects with persistent $\mathrm{BHR}$ com. pared with those with no more BHR $(P=0.015)$.

In multivariate analyses, sensitization to mold allergens at age 6 remained to be independently associated with the persistence of BHR in male adolescents (aOR, 7.718; 95\% CI, 1.24341.440; $P=0.028$ ). Low baseline methacholine $\mathrm{PC}_{20}$ at age 6 was significantly associated with the persistence of BHR in both sex groups. The odds of persistent BHR in adolescence decreased by $19.5 \%$ with each 1 increase of methacholine $\mathrm{PC}_{20}$ at age 6 in males (aOR, 0.805; 95\% CI, 0.715-0.905; $P=0.000$ ) and by $29 \%$ in females (aOR, $0.710 ; 95 \%$ CI, $0.541-0.932 ; P=0.014$ ) (Table 6)

\section{Discussion}

Our study showed sex-specific differences in the factors associated with BHR in adolescence and also in the risk factors for persistent BHR through childhood. Mold sensitization and increased blood eosinophil count were independently associated with BHR only in the male adolescents, but reduced $\mathrm{FEV}_{1} / \mathrm{FVC}$ ratio was associated with BHR only in the female adolescents. 
Table 3. Clinical characteristics of male and female adolescents with or without bronchial hyperresponsiveness

\begin{tabular}{|c|c|c|c|c|c|c|}
\hline \multirow{2}{*}{ Characteristic } & \multicolumn{2}{|c|}{ Males $(n=149)$} & \multirow{2}{*}{$P$ value } & \multicolumn{2}{|c|}{ Females $(n=66)$} & \multirow{2}{*}{$P$ value } \\
\hline & $\mathrm{BHR}(+)(\mathrm{n}=78)$ & $\operatorname{BHR}(-)(n=71)$ & & $\mathrm{BHR}(+)(\mathrm{n}=35)$ & $\operatorname{BHR}(-)(n=31)$ & \\
\hline Age (yr) & $14 \pm 1.9$ & $14 \pm 2.3$ & 1.000 & $15 \pm 3.2$ & $14 \pm 1.8$ & 0.424 \\
\hline \multicolumn{7}{|l|}{ Age at the 1st wheeze started (\%) } \\
\hline$<3 \mathrm{yr}$ & $29(37)$ & $29(41)$ & 0.447 & $13(37)$ & $14(45)$ & 0.618 \\
\hline$\geq 3 \mathrm{yr},<6 \mathrm{yr}$ & $10(13)$ & $12(17)$ & 0.483 & $4(11)$ & $5(13)$ & 0.892 \\
\hline$\geq 6 \mathrm{yr}$ & $39(50)$ & $30(42)$ & 0.354 & $18(52)$ & $12(39)$ & 0.705 \\
\hline Admission with LRI during 1st 3 years of life (\%) & $26(33)$ & $26(37)$ & 0.632 & $11(31)$ & $12(42)$ & 0.446 \\
\hline \multicolumn{7}{|l|}{ Combined allergic disease } \\
\hline Allergic rhinitis & $58(74)$ & $54(77)$ & 0.705 & $23(66)$ & $21(71)$ & 0.652 \\
\hline Atopic dermatitis & $39(50)$ & $27(38)$ & 0.082 & $16(46)$ & $11(35)$ & 0.448 \\
\hline Parental allergic disease & $32(41)$ & $26(38)$ & 0.558 & $13(40)$ & $10(32)$ & 0.541 \\
\hline Atopic sensitization & $74(95)$ & $62(86)$ & 0.091 & $32(91)$ & $28(90)$ & 0.947 \\
\hline House dust mite & $65(88)$ & $52(84)$ & 0.951 & $32(100)$ & $25(89)$ & 0.246 \\
\hline Tree pollen & $34(46)$ & $38(61)$ & 0.081 & $13(41)$ & $13(46)$ & 0.702 \\
\hline Grass pollen & $19(26)$ & $17(27)$ & 0.774 & $6(18)$ & $9(32)$ & 0.348 \\
\hline Weed pollen & $29(39)$ & $28(45)$ & 0.482 & $8(25)$ & $10(35)$ & 0.645 \\
\hline Mold & $26(35)$ & $13(21)$ & 0.047 & $8(25)$ & $6(21)$ & 0.549 \\
\hline Pet & $28(38)$ & $13(21)$ & 0.041 & $11(34)$ & $6(21)$ & 0.149 \\
\hline Food & $10(14)$ & $13(21)$ & 0.257 & $4(13)$ & $4(14)$ & 0.644 \\
\hline Polysensitization & $48(65)$ & $46(74)$ & 0.203 & $20(63)$ & $20(71)$ & 0.518 \\
\hline Total serum IgE (IU/mL), median (IQR) & $388(184-827)$ & $321(132-639)$ & 0.915 & $582(228-1,393)$ & $403(196-818)$ & 0.406 \\
\hline Eosinophil (count $/ \mathrm{mm}^{3}$ ), median (IQR) & $561(279-753)$ & $426(234-691)$ & 0.070 & $539(275-891)$ & $354(171-536)$ & 0.067 \\
\hline Body mass index $\left(\mathrm{kg} / \mathrm{m}^{2}\right)$ & $22.3 \pm 7.6$ & $21.9 \pm 4.1$ & 0.902 & $21.2 \pm 4.1$ & $21.4 \pm 4.0$ & 0.809 \\
\hline Asthma severity ${ }^{\mathrm{a})}$, median (range) & $2(1-4)$ & $1(1-3)$ & 0.079 & $2(1-4)$ & $1(1-4)$ & 0.052 \\
\hline \multicolumn{7}{|l|}{ Pulmonary function test } \\
\hline FEV 1 (\%predicted) & $92 \pm 14.5$ & $94 \pm 18.2$ & 0.476 & $91 \pm 14.5$ & $98 \pm 12.6$ & 0.024 \\
\hline FVC (\%predicted) & $95 \pm 11.8$ & $93 \pm 16.3$ & 0.475 & $92 \pm 17.2$ & $97 \pm 15.1$ & 0.217 \\
\hline $\mathrm{FEV}_{1} / \mathrm{FVC}(\%)$ & $83 \pm 10.3$ & $85 \pm 8.4$ & 0.327 & $85 \pm 11.1$ & $89 \pm 6.4$ & 0.041 \\
\hline$<90$ & $60(77)$ & $46(65)$ & 0.108 & $27(77)$ & $12(39)$ & 0.005 \\
\hline$\geq 90$ & $18(23)$ & $25(35)$ & - & $8(23)$ & $19(61)$ & - \\
\hline Methacholine PC $20(\mathrm{mg} / \mathrm{mL})$, median (IQR) & $5.6(1.3-16)^{b)}$ & NA & - & $5(2.3-16)$ & NA & - \\
\hline$<1$ & $17(22)$ & - & - & $8(23)$ & - & - \\
\hline $1-4$ & $16(20)$ & - & - & $8(23)$ & - & - \\
\hline$>4$ & $45(58)$ & - & - & $19(54)$ & - & - \\
\hline Current asthm ${ }^{\text {c) }}$ & $51(65)$ & $25(35)$ & 0.008 & $24(68)$ & $7(23)$ & 0.003 \\
\hline$P C_{20},<1$ & $12 / 17(70)$ & - & - & $8 / 8(100)$ & - & - \\
\hline$P C_{20}, 1-4$ & $14 / 16(87)$ & - & - & $6 / 8(75)$ & - & - \\
\hline$P C_{20},>4$ & $25 / 45(55)$ & - & - & $10 / 19(53)$ & - & - \\
\hline
\end{tabular}

Values are presented as mean \pm standard deviation or number (\%) unless otherwise indicated.

BHR, bronchial hyperresponsiveness; LRI, lower respiratory infection; IQR, interquartile range; FEV1, forced expiratory volume in 1 second; FVC, forced vital capacity; PC20, provocative concentration of methacholine causing a $20 \%$ fall in forced expiratory volume in 1 second; NA, not available.

a) Asthma severity: 1 , mild-intermittent; 2 , mild-persistent; 3 , moderate-persistent; 4 , severe-persistent. ${ }^{b} P=0.72$ vs. the female group. ${ }^{c}$ Current asthma: episodes of wheeze verified by physicians or asthma exacerbation in the previous year.

Boldface indicates a statistically significant difference with $P<0.05$.

Early mold sensitization at age 6 was an independent risk factor for persistent BHR only in the male subjects.

More than $90 \%$ of the adolescents enrolled in our study had atopic sensitization. This finding is consistent with the results of previous epidemiologic studies that showed sensitization to allergens during early childhood is the most important determinant of persistent asthma by school-age and adolescence. ${ }^{6-10)}$ In the present study, sensitization to HDM, pet, and mold allergens was more prevalent in the subjects with BHR than in those without, but there was no difference in pollen allergy between the 2 groups. Similar to our study, some previous studies have shown that perennial indoor allergens are more influential allergens associated with BHR than seasonal allergens. ${ }^{17-20)}$ Moreover, in our study, multivariate analyses showed that mold sensitization was independently associated with BHR in adolescence with more than 4 times odds. A previous study showed a significant relation between mold sensitization and BHR in Korean children with asthma. ${ }^{21)}$ The prevalence of mold 
Table 4. Multivariate logistic regression analyses of the factors associated with bronchial hyperresponsiveness in male and female adolescents

\begin{tabular}{|c|c|c|c|c|c|c|}
\hline \multirow{2}{*}{ Variable } & \multicolumn{3}{|c|}{ Males $(n=78)$} & \multicolumn{3}{|c|}{ Females $(n=35)$} \\
\hline & $\mathrm{aOR}$ & $95 \% \mathrm{Cl}$ & $P$ value & $\mathrm{aOR}$ & $95 \% \mathrm{Cl}$ & $P$ value \\
\hline $\mathrm{Age}^{\mathrm{a})}$ & 0.683 & $0.510-0.914$ & 0.010 & - & - & - \\
\hline Atopic sensitization & 7.207 & 0.599-86.721 & 0.120 & - & - & - \\
\hline Mold sensitization & 5.569 & $1.702-18.221$ & 0.005 & - & - & - \\
\hline Eosinophil $^{\text {a) }}$ & 1.002 & $1.000-1.003$ & 0.026 & - & - & - \\
\hline $\mathrm{FEV}_{1} / \mathrm{FVC}<90 \%{ }^{\mathrm{b})}$ & - & - & - & 7.500 & $1.715-32.796$ & 0.007 \\
\hline
\end{tabular}

aOR, adjusted odds ratio; $\mathrm{Cl}$, confidence interval; $\mathrm{FEV}_{1}$, forced expiratory volume in 1 second; $\mathrm{FVC}$, forced vital capacity.

Covariates included age, atopic dermatitis, atopic sensitization, tree/mold/pet sensitization, eosinophil count, FEV $\%$, FEV $/$ FVC.

${ }^{\text {a) }}$ Quantitative variables were modeled continuously. ${ }^{\text {b) }}$ Quantitative variables were modeled categorically.

Reference group was $\mathrm{FEV} / / F V C \geq 90 \%$.

Boldface indicates a statistically significant difference with $P<0.05$.

Table 5. Baseline data at age 6 years associated with persistent bronchial hyperresponsiveness throughout childhood in male and female adolescents

\begin{tabular}{|c|c|c|c|c|c|c|}
\hline \multirow[b]{2}{*}{ Variable } & \multicolumn{2}{|c|}{ Males $(n=71)$} & \multirow[b]{2}{*}{$P$ value } & \multicolumn{2}{|c|}{ Females $(n=37)$} & \multirow[b]{2}{*}{$P$ value } \\
\hline & $\begin{array}{l}\text { Persistent BHR } \\
\quad(n=25)\end{array}$ & $\begin{array}{c}\text { No more BHR } \\
(n=46)\end{array}$ & & $\begin{array}{c}\text { Persistent BHR } \\
\quad(n=15)\end{array}$ & $\begin{array}{c}\text { No more BHR } \\
(n=22)\end{array}$ & \\
\hline Age at follow-up (yr) & $14 \pm 1.5$ & $14 \pm 1.4$ & 1.000 & $14 \pm 4.2$ & $14 \pm 1.3$ & 1.000 \\
\hline Age at the 1 st wheeze started (\%) & & & & & & 1.000 \\
\hline$<3 \mathrm{yr}$ & $11(44)$ & $22(48)$ & 0.807 & $6(40)$ & $10(45)$ & \\
\hline$\geq 3 y r_{1}<6 y r$ & $14(56)$ & $24(52)$ & & $9(60)$ & $12(55)$ & \\
\hline Admission with LRI during 1st 3 years of life (\%) & $11(44)$ & $14(30)$ & 0.303 & $4(27)$ & $6(27)$ & 1.000 \\
\hline \multicolumn{7}{|l|}{ Combined allergic disease (\%) } \\
\hline Allergic rhinitis & $19(76)$ & $31(67)$ & 0.588 & $13(87)$ & $15(68)$ & 0.262 \\
\hline Atopic dermatitis & $12(48)$ & $15(33)$ & 0.216 & $6(40)$ & $8(36)$ & 1.000 \\
\hline Parental allergic disease (\%) & $9(36)$ & $22(48)$ & 0.612 & $2(13)$ & $7(32)$ & 0.262 \\
\hline Atopic sensitization (\%) & $22(88)$ & $40(87)$ & 1.000 & $13(87)$ & $18(85)$ & 1.000 \\
\hline House dust mite & $20(90)$ & $34(85)$ & 0.772 & $13(100)$ & $18(100)$ & 1.000 \\
\hline Tree pollen & $13(59)$ & $21(53)$ & 0.807 & $8(62)$ & $6(33)$ & 0.169 \\
\hline Grass pollen & $5(23)$ & $10(25)$ & 0.491 & $6(46)$ & $5(28)$ & 0.295 \\
\hline Weed pollen & $8(36)$ & $17(43)$ & 0.802 & $6(46)$ & $3(17)$ & 0.128 \\
\hline Mold & $8(36)$ & $3(8)$ & 0.013 & $1(7)$ & $3(17)$ & 0.633 \\
\hline Pet & $3(14)$ & $2(5)$ & 0.337 & $3(23)$ & $5(28)$ & 1.000 \\
\hline Food & $3(14)$ & $6(15)$ & 1.000 & $2(15)$ & $3(17)$ & 1.000 \\
\hline Polysensitization & $15(68)$ & $27(67)$ & 1.000 & $9(69)$ & $11(61)$ & 0.386 \\
\hline Total serum IgE (IU/mL), median (IQR) & 379 (223-699) & $238(133-626)$ & 0.457 & $1101(123-1885)$ & $314(148-612)$ & 0.294 \\
\hline Eosinophil (count $\left./ \mathrm{mm}^{3}\right)$, median (IQR) & $561(313-854)$ & $444(259-704)$ & 0.356 & $553(253-1227)$ & $583(284-565)$ & 0.152 \\
\hline Body mass index $\left(\mathrm{kg} / \mathrm{m}^{2}\right)$ & $18.8 \pm 5.8$ & $18.1 \pm 4.3$ & 0.546 & $17.4 \pm 2.8$ & $18.2 \pm 2.6$ & 0.522 \\
\hline \multicolumn{7}{|l|}{ Pulmonary function test } \\
\hline FEV 1 (\%predicted) & $94 \pm 14.5$ & $91 \pm 13.6$ & 0.359 & $87 \pm 9.9$ & $98 \pm 10.3$ & 0.015 \\
\hline FVC (\%predicted) & $93 \pm 9.8$ & $90 \pm 12.6$ & 0.231 & $83 \pm 10.6$ & $91 \pm 14.3$ & 0.194 \\
\hline $\mathrm{FEV}_{1} / \mathrm{FVC}(\%)$ & $87 \pm 8.6$ & $87 \pm 9.2$ & 0.944 & $94 \pm 6.1$ & $93 \pm 9.6$ & 0.731 \\
\hline$<90$ & $15(60)$ & $25(54)$ & 0.803 & $3(20)$ & $6(28)$ & 0.711 \\
\hline$\geq 90$ & $10(40)$ & $21(46)$ & & $12(80)$ & $16(72)$ & \\
\hline Methacholine PC20 (mg/mL), median (IQR) & $2.3(1.2-6.5)$ & $10.5(6.3-13.8)$ & 0.000 & $2.6(1.8-5.8)$ & $9.8(6.4-14.3)$ & 0.007 \\
\hline$<1,1-4$ & $15(60)$ & $6(13)$ & & $10(67)$ & $3(14)$ & \\
\hline$>4$ & $10(40)$ & $40(87)$ & & $5(33)$ & $19(86)$ & NA \\
\hline Methacholine $\mathrm{PC}_{20}$ at follow-up (mg/mL), median (IQR) & $15.2(3.7-19.2)^{a)}$ & NA & & $14.7(4.1-20.3)$ & & \\
\hline
\end{tabular}

Values are presented as mean \pm standard deviation or number (\%) unless otherwise indicated.

BHR, bronchial hyperresponsiveness; LRI, lower respiratory infection; IQR, interquartile range; FEV 1 , forced expiratory volume in 1 second; FVC, forced vital capacity; PC20, provocative concentration of methacholine causing a $20 \%$ fall in forced expiratory volume in 1 second; NA, not available.

a) $P=0.826$ vs. female group.

Boldface indicates a statistically significant difference with $P<0.05$. 
Table 6. Multivariate logistic regression analyses of the baseline factors at age 6 years associated with persistent bronchial hyperresponsiveness in male and female adolescents

\begin{tabular}{|c|c|c|c|c|c|c|}
\hline \multirow{2}{*}{ Variable } & \multicolumn{3}{|c|}{ Males $(n=25)$} & \multicolumn{3}{|c|}{ Females $(n=15)$} \\
\hline & $\mathrm{aOR}$ & $95 \% \mathrm{Cl}$ & $P$ value & $\mathrm{aOR}$ & $95 \% \mathrm{Cl}$ & $P$ value \\
\hline Mold sensitization & 7.718 & $1.243-41.440$ & 0.028 & & & \\
\hline Methacholine $\mathrm{PC}_{20}{ }^{\mathrm{a}}$ ) & 0.805 & $0.715-0.905$ & 0.000 & 0.710 & $0.541-0.932$ & 0.014 \\
\hline
\end{tabular}

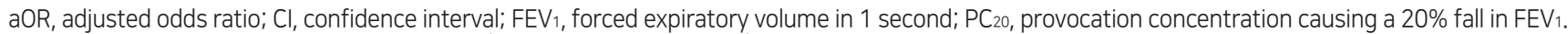
Covariates included mold sensitization, $\mathrm{FEV}_{1} \%^{\mathrm{a}}$, , and methacholine $\mathrm{PC}_{20}{ }^{\mathrm{a}}$.

${ }^{a)}$ Quantitative variables were modeled continuously.

Boldface indicates a statistically significant difference with $P<0.05$.

sensitization in those school-age children was $12.2 \%$, which was comparable to $25 \%$ in our adolescents with childhood asthma. There was another Korean study that showed a significant association between sensitization to Alternaria and BHR in adult patients. ${ }^{20)}$ Together with the 2 previous Korean studies, our findings suggest that mold sensitization might be a risk factor in transition of childhood asthma into adolescence and adulthood.

In the present study, increased blood eosinophil count was independently associated with BHR in adolescence. The previous studies have reported the relationship between elevated blood eosinophil count and BHR, ${ }^{22-25)}$ and one of them showed that blood eosinophil count was significantly higher in asymptomatic adolescents with BHR than in those without. ${ }^{25)}$ Our study showed that the adolescents with BHR had more severe airflow limitation compared with those without, and in multivariate analyses, reduced $\mathrm{FEV}_{1} / \mathrm{FVC}$ ratio $(<90 \%)$ was independently associated with BHR. A recent report from CAMP study showed that the severity of airflow obstruction in asthmatic children, presented as $\mathrm{FEV}_{1} / \mathrm{FVC}$ ratio, was the greatest predictor of asthma remission in young adulthood ${ }^{15)}$ and our findings seem to support it. In our study, current asthma was independently associated with the presence of BHR, but $34 \%$ of the adolescents with BHR showed no current asthma. A previous study has reported that asymptomatic BHR in adolescence was associated with relapse of asthma in adulthood. ${ }^{8)}$ Taken together with the results of the previous studies, our results suggest that evaluation of BHR and airflow limitation is needed in the adolescents who had childhood asthma.

In addition to these overall findings, our study showed sexspecific differences in the factors associated with BHR in the adolescents with childhood asthma. In multivariate analyses, increased blood eosinophil count was independently associated with BHR in the male subjects, but not in the female subjects. Our finding seems to support the results of CAMP study which showed that a significant association between low blood eosinophil count and asthma remission in adulthood was observed only in the male subjects. ${ }^{15)}$ It is well known that atopy is closely associated with BHR. The male subjects of our study showed a positive relationship between sensitization to some inhalant allergens and BHR, and especially, mold sensitization was independently associated with BHR. However, the female subjects showed no relationship between atopic sensitization and BHR. Similar to our findings, there was a general population study which reported that atopy was a significant risk factor of BHR in boys during puberty, but not in girls. ${ }^{26)}$ Our results suggest that there might be difference in the impact of atopy on BHR between male and female adolescents.

In the present study, multivariate analyses showed that the risk of BHR decreased by $32 \%$ with each 1 year increase of age in males, which was not observed in females. Our findings seem to be consistent with those of a previous study which showed a greater increase of postpubertal methacholine $\mathrm{PC}_{20}$ with age in boys compared with girls. ${ }^{27)}$ In our study, more severe airflow limitation was observed in the female subjects with BHR than in those without, and multivariate analyses showed that reduced $\mathrm{FEV}_{1} / \mathrm{FVC}$ ratio $(<90 \%)$ was independently associated with BHR only in the female subjects. Many studies have reported that surges in endogenous sex hormones across adolescence could affect BHR and lung function. ${ }^{9,10,28-32)}$ Female sex hormones are known to play a regulatory role in asthma pathophysiology, but many conflicting results have been described about pro- or anti-inflammatory effects of estrogen and progesterone. ${ }^{33)} \mathrm{A}$ recent study in adolescents with asthma showed that androgens positively, but estrogens negatively associated with lung function. ${ }^{28)}$ In that study, lung function in females became worse compared with males during adolescence, which might be associated with dysanaptic pattern of airway growth, that is to say, differential growth of airway caliber and lung volume, due to female sex hormone. ${ }^{28)}$ Our results showed that the relationship between airflow limitation and BHR was different between the male and female adolescents, and seem to support those previous findings.

In the present study, we observed the longitudinal decrease in BHR through childhood and adolescence, and 37\% of the asthmatic children who had BHR at age 6 showed persistent BHR. Multivariate analyses showed that low baseline methacholine $\mathrm{PC}_{20}$ at age 6 was an independent risk factor for the persistence of BHR in both male and female adolescents. Previously, Tucson Children's Respiratory Study reported that sensitization to Alternaria, an important asthma-associated allergen in Tucson area, at age 6 was an independent predictor of chronic asthma at age 22.7 In our study, HDM was the major allergen and sensitization rate to mold allergens was relatively low at age 6 . However, multivariate analyses revealed that early sensitization to mold allergens at age 6 was an independent risk factor for persistent BHR through childhood, and this relationship was observed only in the male subjects. Many studies have shown the close relationship between atopy and BHR in 
both childhood and adolescent asthma. Our study also showed that almost $90 \%$ of the asthmatic children with BHR at age 6 had atopic sensitization. However, to the best of our knowledge, our results suggest first that we need to pay more attention to the boys who had early mold sensitization at age 6 because they might have persistent BHR in adolescence.

There are several limitations in the present study. First, as it was a single-center study, the number of the enrolled adolescents who had childhood asthma was relatively small and may have selection bias. Second, we observed that mold sensitization was independently associated with BHR, but we could not investigate the effect of individual mold species in this study. Although Alternaria and Aspergillus are known to be the most common mold allergens in Korea, we think further studies are needed to clarify the association between sensitization to specific mold allergen and BHR in adolescents. Lastly, we could not analyze the effect of environmental tobacco smoke or active smoking on the presence or persistence of BHR in the adolescents.

In conclusion, our study showed sex-specific differences in the factors associated with BHR in the adolescents who had childhood asthma and also in the risk factors for persistent BHR through childhood. Independent association between mold sensitization and BHR in adolescence was observed only in the male subjects on both cross-sectional and longitudinal analyses. Our results suggest the risk factors that might be involved in the transition of asthma from childhood into adolescence and adulthood.

\section{Conflicts of interest}

No potential conflict of interest relevant to this article was reported.

\section{ORCID}

Yoon Young Jang $@$ https://orcid.org/0000-0002-0151-9758

Jieun Jeong @ https://orcid.org/0000-0002-3036-6818

Hai Lee Chung $@$ https://orcid.org/0000-0002-5364-5318

\section{References}

1. Bateman ED, Hurd SS, Barnes PJ, Bousquet J, Drazen JM, FitzGerald JM, et al. Global strategy for asthma management and prevention: GINA executive summary. Eur Respir J 2008;31:143-78.

2. Palmer LJ, Rye PJ, Gibson NA, Burton PR, Landau LI, Lesouëf PN. Airway responsiveness in early infancy predicts asthma, lung function, and respiratory symptoms by school age. Am J Respir Crit Care Med 2001;163:37-42.

3. Toelle BG, Xuan W, Peat JK, Marks GB. Childhood factors that predict asthma in young adulthood. Eur Respir J 2004;23:66-70.

4. Vonk JM, Postma DS, Boezen HM, Grol MH, Schouten JP, Koëter GH, et al. Childhood factors associated with asthma remission after 30 year follow up. Thorax 2004;59:925-9.

5. van den Toorn LM, Overbeek SE, de Jongste JC, Leman K, Hoogsteden HC, Prins JB. Airway inflammation is present during clinical remission of atopic asthma. Am J Respir Crit Care Med 2001;164:2107-13.

6. Fuchs O, Bahmer T, Rabe KF, von Mutius E. Asthma transition from childhood into adulthood. Lancet Respir Med 2017;5:224-34.
7. Stern DA, Morgan WJ, Halonen M, Wright AL, Martinez FD. Wheezing and bronchial hyper-responsiveness in early childhood as predictors of newly diagnosed asthma in early adulthood: a longitudinal birth-cohort study. Lancet 2008;372:1058-64.

8. Sears MR, Greene JM, Willan AR, Wiecek EM, Taylor DR, Flannery EM, et al. A longitudinal, population-based, cohort study of childhood asthma followed to adulthood. N Engl J Med 2003;349:1414-22.

9. Ross KR, Teague WG, Gaston BM. Life cycle of childhood asthma: prenatal, infancy and preschool, childhood, and adolescence. Clin Chest Med 2019;40:125-47.

10. Withers AL, Green R. Transition for adolescents and young adults with asthma. Front Pediatr 2019;7:301.

11. Crapo RO, Casaburi R, Coates AL, Enright PL, Hankinson JL, Irvin CG, et al. Guidelines for methacholine and exercise challenge testing-1999. Am J Respir Crit Care Med 2000;161:309-29.

12. Nicolai T, Illi S, Tenbörg J, Kiess W, v Mutius E. Puberty and prognosis of asthma and bronchial hyper-reactivity. Pediatr Allergy Immunol 2001; $12: 142-8$.

13. Riiser A, Hovland V, Mowinckel P, Carlsen KH, Carlsen KL. Bronchial hyper-responsiveness decreases through childhood. Respir Med 2012; 106:215-22.

14. Lee E, Kim YH, Han S, Yang SI, Jung YH, Seo JH, et al. Different cutoff values of methacholine bronchial provocation test depending on age in children with asthma. World J Pediatr 2017;13:439-45.

15. Wang AL, Datta S, Weiss ST, Tantisira KG. Remission of persistent childhood asthma: early predictors of adult outcomes. J Allergy Clin Immunol 2019;143:1752-9.

16. Suh DI, Yang HJ, Kim BS, Shin YH, Lee SY, Park G, et al. Asthma severity and the controller prescription in children at 12 tertiary hospitals. Allergy Asthma Immunol Res 2017;9:52-60.

17. Langley SJ, Goldthorpe S, Craven M, Morris J, Woodcock A, Custovic A. Exposure and sensitization to indoor allergens: association with lung function, bronchial reactivity, and exhaled nitric oxide measures in asthma. J Allergy Clin Immunol 2003;112:362-8.

18. Kerkhof M, Postma DS, Schouten JP, de Monchy JG. Allergic sensitization to indoor and outdoor allergens and relevance to bronchial hyperresponsiveness in younger and older subjects. Allergy 2003;58:1261-7.

19. Craig TJ, King TS, Lemanske RF Jr, Wechsler ME, Icitovic N, Zimmerman RR Jr, et al. Aeroallergen sensitization correlates with PC (20) and exhaled nitric oxide in subjects with mild-to-moderate asthma. J Allergy Clin Immunol 2008;121:671-7.

20. Jo EJ, Kim MY, Lee SE, Lee SY, Kim MH, Song WJ, et al. Eosinophilic airway inflammation and airway hyperresponsiveness according to aeroallergen sensitization pattern in patients with lower airway symp toms. Allergy Asthma Immunol Res 2014;6:39-46.

21. Byeon JH, Ri S, Amarsaikhan O, Kim E, Ahn SH, Choi IS, et al. Association between Sensitization to mold and impaired pulmonary function in children with asthma. Allergy Asthma Immunol Res 2017;9:509-16.

22. Zeiger RS, Schatz M, Li Q, Chen W, Khatry DB, Gossage D, et al. The association of blood eosinophil counts to future asthma exacerbations in children with persistent asthma. J Allergy Clin Immunol Pract 2015;3: 283-7

23. Malinovschi A, Fonseca JA, Jacinto T, Alving K, Janson C. Exhaled nitric oxide levels and blood eosinophil counts independently associate with wheeze and asthma events in National Health and Nutrition Examination Survey subjects. J Allergy Clin Immunol 2013;132:821-7.

24. Malinovschi A, Janson C, Borres M, Alving K. Simultaneously increased fraction of exhaled nitric oxide levels and blood eosinophil counts relate to increased asthma morbidity. J Allergy Clin Immunol 2016;138:13018.

25. Schwartz N, Grossman A, Levy Y, Schwarz Y. Correlation between eosinophil count and methacholine challenge test in asymptomatic subjects. J Asthma 2012;49:336-41.

26. Kim YH, Lee E, Cho HJ, Yang SI, Jung YH, Kim HY, et al. Association between menarche and increased bronchial hyper-responsiveness during puberty in female children and adolescents. Pediatr Pulmonol 2016; 51:1040-7. 
27. Tantisira KG, Colvin R, Tonascia J, Strunk RC, Weiss ST, Fuhlbrigge AL, et al. Airway responsiveness in mild to moderate childhood asthma: sex influences on the natural history. Am J Respir Crit Care Med 2008;178: 325-31.

28. DeBoer MD, Phillips BR, Mauger DT, Zein J, Erzurum SC, Fitzpatrick $\mathrm{AM}$, et al. Effects of endogenous sex hormones on lung function and symptom control in adolescents with asthma. BMC Pulm Med 2018; 18:58.

29. Zein JG, Erzurum SC. Asthma is different in women. Curr Allergy Asthma Rep 2015;15:28.

30. Farha S, Asosingh K, Laskowski D, Hammel J, Dweik RA, Wiedemann $\mathrm{HP}$, et al. Effects of the menstrual cycle on lung function variables in women with asthma. Am J Respir Crit Care Med 2009;180:304-10.

31. Cephus JY, Stier MT, Fuseini H, Yung JA, Toki S, Bloodworth MH, et al. Testosterone Attenuates Group 2 innate lymphoid cell-mediated airway inflammation. Cell Rep 2017;21:2487-99.
32. Kouloumenta V, Hatziefthimiou A, Paraskeva E, Gourgoulianis K, Molyvdas PA. Non-genomic effect of testosterone on airway smooth muscle. Br J Pharmacol 2006;149:1083-91.

33. van den Berge M, Heijink HI, van Oosterhout AJ, Postma DS. The role of female sex hormones in the development and severity of allergic and nonallergic asthma. Clin Exp Allergy 2009;39:1477-81.

How to cite this article: Kim YH, Jang YY, Jeong J, Chung HL. Sex-based differences in factors associated with bronchial hyperresponsiveness in adolescents with childhood asthma. Clin Exp Pediatr 2021;64:229-38. https://doi.org/10.3345/cep. 2020.01585 